to ${ }^{0.30}$ "weak" scales, while values of $<^{0.30}$ are not considered as unidimensional. Internal consistency (reliability) was assessed using Cronbach's a.

The validation sample comprised ${ }^{79}$ patients $\left({ }^{74} . \%\right.$ female $)$ with a median age of ${ }^{61}$ (IQR: ${ }^{49}$ to ${ }^{71}$ ) and disease duration of ${ }^{8}$ (IQR: ${ }^{4}$ to ${ }^{13}$ ) years. Table ${ }^{1}$ presents the results of validation with Mokken model. The construct validity of the revised German SScQoL was confirmed in all subscales and the global scale. The scalability ( $H$ coefficients) were all above ${ }^{0.50}$ suggesting a robust unidimensional scale. Internal consistency was high (Cronbach's $\alpha={ }^{0.97}$ ).

Background: The Systemic Sclerosis Quality of Life Questionnaire (SScQoL) has been validated in six European languages. ${ }^{1}$ Previous adaptation into German revealed issues with the dichotomous response structure in 10 items necessitating a review of the tool and further psychometric testing with patients in German speaking countries.

Objectives: The aim of this study was to assess the German version of the SScQoL, extend the response structure and test its construct validity using Mokken scale analysis.

Methods: This was a mixed methods study involving cognitive debriefing and survey methods. The expert committee extended the response structure of the 10 items from dichotomous to polytomous (4-point) responses: 'always', 'usually', 'sometimes' and 'never'. In cognitive debriefing, a small convenience sample of patients with SSc completed the new version while 'thinking aloud' and commented on relevance of the items and the response structure.

Results: In cognitive debriefing, six patients with SSc completed the new German SScQoL and reported problems with the remaining dichotomous items. These were subsequently converted into polytomous 4-point response structure by the expert committee.

Conclusion: The German SScQoL has been revised into polytomous item structure and shown to be a valid and reliable measure of health-related quality of life in SSc. Further cross-cultural validity tests are required to assess its measurement equivalence with other SScQoL versions and thus enable multinational comparisons.

References:

[1] Ndosi M, Alcacer-Pitarch B, Allanore $Y$ et al. Common measure of quality of life for people with systemic sclerosis across seven European countries: a cross-sectional study. Ann Rheum Dis, 2018; 77: 1032-1038

Table 1. Mokken scale analysis of the revised German SScQoL

\begin{tabular}{lcc}
\hline $\begin{array}{l}\text { Subscale } \\
\text { (items) }\end{array}$ & Scalability $(\mathbf{H})$ & Standard error \\
\hline Function (6) & 0.664 & 0.048 \\
Emotional (13) & 0.652 & 0.060 \\
Sleep (2) & 0.798 & 0.061 \\
Social (6) & 0.692 & 0.053 \\
Pain (2) & 0.960 & 0.029 \\
Global scale (29) & 0.623 & 0.062
\end{tabular}

Table legend: scalability $H \geq 0.50=$ strong, 0.49 to $0.40=$ moderate, 0.39 to $0.30=$ weak, while values of $<0.30$ are not considered as unidimensional.

Disclosure of Interests: Agnes Kocher Grant/research support from: Sandoz to support the development of an eLearning module for patients with rheumatic diseases., Mwidimi Ndosi Grant/research support from: Bristol Myers Squibb, Consultant of: Janssen, Pfizer, Kirsten Hoeper Consultant of: AbbVie, Celgene,, Speakers bureau: Abbvie, Chugai, Novartis, Lilly, Celgene, Sandoz Hexal, Michael Simon: None declared, Dunja Nicca: None declared

DOI: 10.1136/annrheumdis-2020-eular.1156

\section{THU0624-HPR COMPARISON OF WRIST PROPRIOCEPTION, GRIP STRENGTH AND PINCH STRENGTH IN PATIENTS WITH PSORIATIC ARTHRITIS AND RHEUMATOID ARTHRITIS: PRELIMINARY STUDY}

M. Köprülüoğlu' ${ }^{1}$ I. Naz Gürşan ${ }^{1}$, D. Solmaz ${ }^{2}$, E. Otman², E. Durak Ediboglu², S. Akar ${ }^{2}{ }^{1}$ Izmir Katip Celebi University, Faculty of Health Sciences, Department of Physiotherapy, izmir, Turkey; ${ }^{2}$ Izmir Katip Celebi University, Faculty of Medicine, Department of Rheumatology, Izmir, Turkey

Background: Hand articular damage occurs in rheumatoid arthritis (RA) and functional ability deteriorates as the disease progresses. Limitation of hand motion, oedema, pain etc. factors contribute to reduce grip strength, pinch strength and joint position sense; this problems contribute to function and disability. Following RA, affecting grip and pinch strength (1) and joint position sense (2) was reported former research. But there is a little knowledge about disabilitiy of hand functions in psoriatic arthritis (PsA).
Objectives: To compare joint position sense, grip strength and pinch strength in patient with PsA and RA.

Methods: In our cross sectional study, 23 RA patients [Mean age; $52.7 \pm 12.6$, Women:20(87.0\%)] who were classified according to the ACR 2010 criteria and 19 PsA patients [Mean age $53.5 \pm 12.6$, Women:14 (\%73.7)] who were classified according to the CASPAR criteria were included.It was recorded demographic and clinical data of patients. Wrist position sense was evaluated by goniometric re-position error test (in 30 ${ }^{\circ}$ wrist extansion, 3 repeat). Grip strenght was examined using a hand dynamometer (Lafayette Proffessional Hand Dynamometer, USA) and pinch strength (two point, three point, lateral) was evaluated by pinchmeter (Lafayette,USA).

Results: Patients were similar in terms of age, gender, disease duration, morning stiffness duration, pain of hand joints, number of tender and swallen joints and disease activity $(p>0.05)$. RA patients had longer disease duration $(p=0.004)$ and lower ESR levels $(p=0.046)$ compared to PsA. Grip and pinch strength were found similar in both dominant and non-dominant side between RA and PsA patients (Table 1). Wrist joint position error was higher in PsA group in non-dominant side $(p=0.011)$.

Table 1. Comparison of Groups for Grip and Pinch Strength and Joint Position Sense

\begin{tabular}{lccc}
\hline Variables & $\begin{array}{c}\text { RA }(\mathbf{n}=\mathbf{2 3}) \\
\text { Median(IQR) }\end{array}$ & $\begin{array}{c}\text { PsA (n=19) } \\
\text { Median(IQR) }\end{array}$ & $\mathbf{p}^{*}$ \\
\hline Grip Strength & $20(14 / 25)$ & $25(20 / 29)$ & 0.109 \\
Dominant & $20(14 / 25)$ & $21(15 / 26)$ & 0.404 \\
Non-dominant & & & \\
Pinch Strength & $3.1(2.2 / 3.8)$ & $3(2.2 / 3.4)$ & 0.810 \\
Dominant & $3(2.3 / 4.0)$ & $3.4(2.5 / 4.20)$ & 0.471 \\
2 Point & $3.4(3.0 / 4.2)$ & $3.5(2.6 / 4.5)$ & 0.840 \\
3 Point & $3(1.9 / 3.7)$ & $3(2.4 / 3.7)$ & 0.714 \\
Lateral & $2.8(2.3 / 3.8)$ & $3.1(2.3 / 4.2)$ & 0.723 \\
Nondominant & $2.9(2.5 / 4.0)$ & $3.2(2.4 / 4.2)$ & 0.561 \\
2 Point & & & \\
3 Point & & & \\
Lateral & & & \\
Joint Position Error & $6(5 / 7)$ & & \\
Dominant & $6(3 / 8)$ & & \\
Non-dominant & & & \\
\hline
\end{tabular}

Data have shown as median (interquartile range 25-75) *Mann Whitney-U Test

Conclusion: Our study showed that patients with PsA had hand impairment as much as RA patients. We think, hand assessment in patients with PsA rehabilitation programme is essential for clinicians. There is need future studies including asymptomatic healthy group to interpret of results in detailed.

References:

[1] VLIET, TP Vlieland, et al. Determinants of hand function in patients with rheumatoid arthritis. The Journal of rheumatology, 1996, 23.5: 835-840.

[2] FERRELL, W. R.; CRIGHTON, A.; STURROCK, R. D. Position sense at the proximal interphalangeal joint is distorted in patients with rheumatoid arthritis of finger joints. Experimental Physiology: Translation and Integration, 1992, 77.5: 675-680.

Disclosure of Interests: None declared

DOI: 10.1136/annrheumdis-2020-eular.4257

\section{THU0625-HPR ELECTRONIC PATIENT-REPORTED OUTCOMES: A SURVEY ABOUT ACCEPTANCE, USAGE AND BARRIERS AMONG GERMAN RHEUMATOLOGISTS}

M. Krusche ${ }^{1}$, P. Klemm², M. Grahammer ${ }^{3}$, J. Mucke ${ }^{4}$, D. Vossen ${ }^{5}$, A. Kleyer ${ }^{6}$ P. Sewerin ${ }^{7}$, J. Knitza ${ }^{8} .{ }^{1}$ Charité - Universitätsmedizin Berlin, Department of Rheumatology and Clinical Immunology, Berlin, Germany; ${ }^{2}$ Kerckhoff-Klinik, Department of Rheumatology, Immunology, Osteology and Physical Medicine, Bad Nauheim, Germany; ${ }^{3}$ ABATON GmbH, Berlin, Germany; ${ }^{4}$ Heinrich Heine University Düsseldorf, Department of Rheumatology and Hiller Research Unit Rheumatology, Düsseldorf, Germany; ${ }^{5}$ Rheinisches Rheumazentrum Meerbusch, Meerbusch, Germany; ${ }^{6}$ Friedrich-Alexander-University Erlangen-Nuremberg Institute for Sport Science and Sport, Department of Internal Medicine ${ }^{3}$ - Rheumatology and Immunology, Erlangen, Germany; ${ }^{7}$ Heinrich Heine University Düsseldorf, Department of Rheumatology and Hiller Research Unit Rheumatology, Düsseldorf, Germany; ${ }^{8}$ Findelgasse FAU, Department of Internal Medicine ${ }^{3}$ - Rheumatology and Immunology, Nürnberg, Germany

Background: The use of patient-reported outcomes (PROs) allows for patient-centered, measurable and transparent care. Electronic PROs (ePROs) have many benefits and hold great potential to improve current usage of PROs; 
yet, limited evidence exists regarding acceptance, usage and barriers among rheumatologists.

Objectives: This study aimed to evaluate the current level of acceptance, usage, and barriers among German rheumatologists regarding the utilization of ePROs. The importance of different ePRO features for rheumatologists was investigated. Additionally, the most frequently used PROs for patients with rheumatoid arthritis (RA) were identified

Methods: Data was collected via an online survey consisting of 18 questions. The survey was completed by members of the Working Group Young Rheumatologists of the German Society for Rheumatology (Deutsche Gesellschaft für Rheumatologie (DGRh)) at the annual 2019 DGRh conference. Only members currently working in clinical rheumatology were eligible to complete the survey. Results: A total of 119 rheumatologists completed the survey. $90 \%$ reported collecting PROs in routine practice and $25.5 \%$ already used ePROs. $44.3 \%$ were planning to switch to ePROs in the near future.The main reason for collecting PROs was for clinical decision making (66.4\%), followed by research (39.5\%), reimbursement $(23.5 \%)$, internal quality management $(21.9 \%)$ and patient satisfaction (16.8\%). The most commonly cited reason for not switching to ePROs was the unawareness of suitable software solutions (figure 1).Respondents were asked to rate the features for ePROs on a scale of $0-100(0=$ unimportant, $100=$ important). The most important features were automatic score calculation and display (score: 77.5), as well as the simple data transfer to medical reports (76.9) (table 1). When asked about PROs in RA, the respondents listed pain, morning stiffness and physician global assessment (PGA) as the most frequently used PROs (figure 2).

Table 1. Ratings for features of ePRO on a scale of 0-100 (0 = unimportant, 100 = important))

\begin{tabular}{|c|c|c|}
\hline Question & mean & SD \\
\hline How important would the graphic display be to you for ePROs? & 63.5 & 31.19 \\
\hline $\begin{array}{l}\text { How important would the automatic score calculation and display of ePROs } \\
\text { be to you? }\end{array}$ & 77.5 & 27.64 \\
\hline $\begin{array}{l}\text { How important would the simple transfer of the ePROs in medical report be } \\
\text { to you? }\end{array}$ & 76.9 & 30.07 \\
\hline $\begin{array}{l}\text { How important would an automatic alarm of yourself be for you if a critical } \\
\text { threshold is exceeded by an ePRO? }\end{array}$ & 51.65 & 33.5 \\
\hline $\begin{array}{l}\text { How important would an automatic alarm of the patient be for you if a critical } \\
\text { threshold is exceeded by an ePRO? }\end{array}$ & 34.55 & 30.61 \\
\hline
\end{tabular}

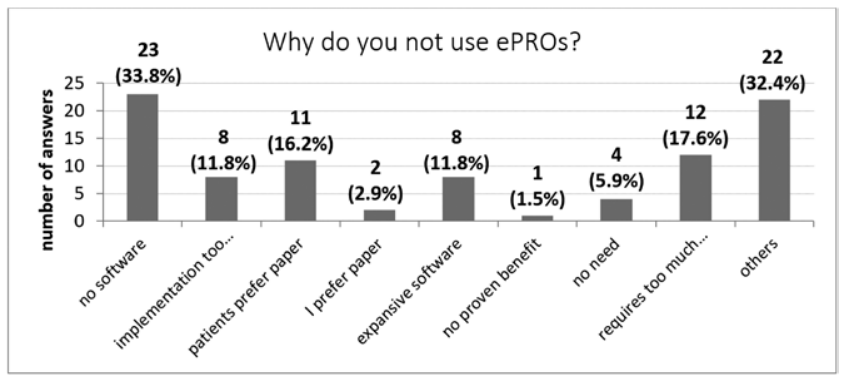

Figure 1. Reasons why ePROs are currently not used (multiple answers were possible for question)

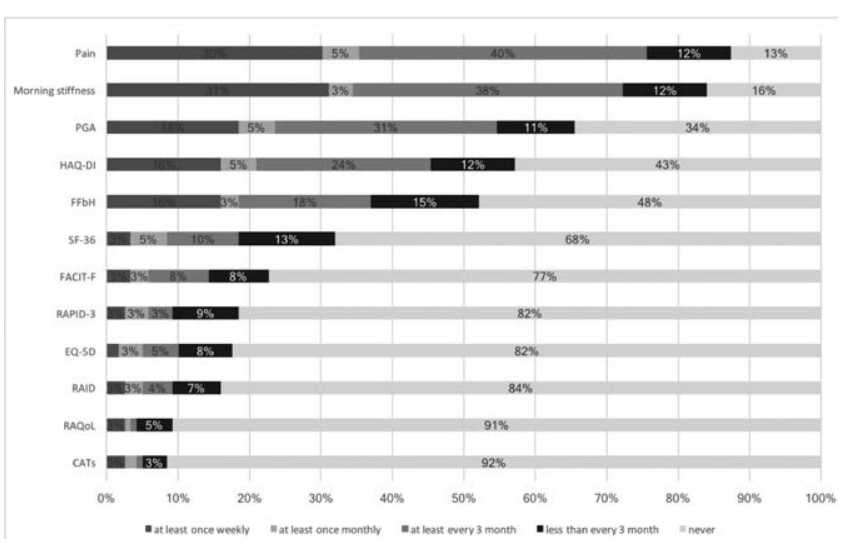

Figure 2. PROs being used in clinical practice and their respective frequency
Conclusion: The potential of ePROs is widely seen, and there is a great interest in ePROs. Despite this, a minority of physicians only uses ePROs, and the main reason for not implementing was cited as the unawareness of suitable software solutions.

Developers, patients and rheumatologists should work closely together to help realize the full potential of ePROs and ensure a seamless integration into clinical practice.

Disclosure of Interests: Martin Krusche Consultant of: Sanofi, Novartis and Medac, Speakers bureau: Roche/Chugai, Novartis, Sobi,, Philipp Klemm Consultant of: Lilly, Medac, Manuel Grahammer Shareholder of: MG is MD and shareholder of Abaton $\mathrm{GmbH}$, Johanna Mucke: None declared, Diana Vossen Consultant of: Medac, Novartis, Abvie, Speakers bureau: Abvie, BMS, Arnd Kleyer Consultant of: Lilly, Gilead, Novartis,Abbvie, Speakers bureau: Novartis, Lilly, Philipp Sewerin Grant/research support from: AbbVie Deutschland GmbH \& Co. KG

Bristol-Myers Squibb Celgene $\mathrm{GmbH}$

Lilly Deutschland $\mathrm{GmbH}$

Novartis Pharma GmbH Pfizer Deutschland GmbH

Rheumazentrum Rhein-Ruhr, Consultant of: AMGEN GmbH AbbVie Deutschland $\mathrm{GmbH}$ \& Co. KG Biogen GmbHBristol-Myers Squibb Celgene GmbH Chugai Pharma arketing Ltd. / Chugai Europe GmbHHexal Pharma Janssen-CilagGmbH Johnson \& Johnson Deutschland GmbHLilly Deutschland GmbH / Lilly Europe / Lilly Global Novartis Pharma GmbH Pfizer Deutschland $\mathrm{GmbH}$ Roche Pharma Rheumazentrum Rhein-Ruhr Sanofi-Genzyme Deutschland GmbH Swedish Orphan Biovitrum GmbH UCB Pharma GmbH, Speakers bureau: AMGEN GmbH AbbVie Deutschland GmbH \& Co. KG Biogen GmbHBristol-Myers Squibb Celgene GmbH Chugai Pharma arketing Ltd. / Chugai Europe GmbHHexal Pharma Janssen-CilagGmbH Johnson \& Johnson Deutschland GmbHLilly Deutschland GmbH / Lilly Europe / Lilly Global Novartis Pharma $\mathrm{GmbH}$ Pfizer Deutschland $\mathrm{GmbH}$ Roche Pharma Rheumazentrum Rhein-Ruhr Sanofi-Genzyme Deutschland GmbH Swedish Orphan Biovitrum GmbH UCB Pharma GmbH, Johannes Knitza Grant/research support from: Research Grant: Novartis

DOI: 10.1136/annrheumdis-2020-eular.3746

\section{THU0626-HPR IMPORTANCE OF A SYSTEMATIC COGNITIVE ASSESSMENT: IMPLEMENTATION OF A COGNITIVE EVALUATION AND REHABILITATION CLINIC IN RHEUMATIC PATIENTS}

A. Moreno-Salinas ${ }^{1}$, M. E. Corral Trujillo', I. D. J. Hernandez-Galarza', C. V. Solis ${ }^{1}$, A. S. Leal Bramasco ${ }^{1}$, L. Santoyo-Fexas ${ }^{1}$, D. Á. Galarza-Delgado'.

'University Hospital "Dr. José Eleuterio González"UANL, Rheumatology, Monterrey, Mexico

Background: Cognition is the ability to learn, process and remember information to be used later.(1) Cognitive impairment reflects a decrease in one or more cognitive domains: memory, language, reasoning, among others. (2) It has been reported in rheumatic diseases such as systemic lupus erythematosus, rheumatoid arthritis, fibromyalgia, and it is frequently found in young patients during the first years of their illness correlating the disease progression.(3) This condition can lead to anxiety and depression, compromising the quality of life. Given the lack of consensus regarding the best test to diagnose cognitive impairment, multiple tools have been used to address this problem.

Objectives: To describe the systematical assessment in a Cognitive Evaluation and Rehabilitation Clinic in rheumatic patients from a University Hospital in Mexico.

Methods: Observational and descriptive study. A multidisciplinary team met for 6 months to establish the structure a Cognitive Evaluation and Rehabilitation Clinic in a University Hospital in Mexico (Figure 1). As a pilot group we included outpatients from a Rheumatology clinic, referred

Table 1. Demographic characteristics

\begin{tabular}{lc}
\hline & $\mathrm{N}=\mathbf{2 1}$ \\
\hline Age, mean (SD) & $43.62(14.68)$ \\
Female, $\mathrm{n}(\%)$ & $14(66.66)$ \\
Years of education, mean (SD) & $15.24(2.70)$ \\
$\begin{array}{l}\text { Psychiatric disorder } \\
\text { Depression, } \mathrm{n}(\%)\end{array}$ & $4(19.04)$ \\
Rheumatic diagnosis & $13(61.90)$ \\
Systemic lupus erythematosus, $n$ (\%) & $3(14.30)$ \\
Rheumatoid arthritis, $n(\%)$ & $5(23.80)$ \\
\hline
\end{tabular}

